\title{
Humanin, MOTS-c and physical exercise: A new perspective
}

\author{
Alyson RB Monteiro ${ }^{1}$, Gabriel CG Scarlato ${ }^{2}$, Diego F Cavalini ${ }^{2}$ and Gilberto E Shiguemoto ${ }^{1,2 *}$ \\ ${ }^{1}$ Postgraduate Program of Physioterapy, Federal University of São Carlos - UFSCar, Brazil \\ ${ }^{2}$ Interinstitutional Postgraduate Program in Physiological Sciences, Department of Physiological Sciences, Federal University of São Carlos - UFSCar, Brazil
}

\begin{abstract}
Energy is frequently defined as the ability to perform work, and every work demands some sort of movement. The biggest part of these energetic transformations bioenergetic goes through the mitochondria with also develop an important role as integrators of a variety of intracellular signals. Besides that, this interesting organelle is considered an important local generator of systemic responses. New evidence has pointed the discovery of two peptides named Humanin and mitochondrial Open Reading Frames (ORF) of the twelve S c (MOTS-c), which are derivative from mtDNA and have an important systemic performance. Few works have accomplished studies regarding mitochondrial systemic responses practiced by mitochondrial peptides faced with controlled stress, such as physical stress. Therefore, the goal of this review is to describe the biological effects of these two mitochondrial peptides as well as possible benefic interactions between them and the physical exercise. Thus, we hope that the present review may raise the interest of new clinical studies that better investigate the responses of this new class of peptides faced intervention of the physical exercise, considering the correct manipulation of the components of the training load that modulate both Humanin's response and MOTS-c's response, with therapeutic potential in combating various diseases.
\end{abstract}

\section{Introduction}

Energy is frequently defined as the ability to perform work, and every work demands some sort of movement. Biologically, energy is responsible for supporting the muscular work, crucial for various beings since it sustains vital processes, such as breathing, swallowing, locomotion, development and reproduction [1]. Such activities are only possible because of the energy flow, which sustains every molecular organization required for the complexity of life $[2,3]$.

Energy is conserved and cannot be created or destroyed, but instead of it suffers constant transformations, tending to always stabilize itself in the smallest energetic state [1]. For example, food contains potential energy, being when we consume them this energy is absorbed and used to produce movements, heat and other organic functions; the energy difference between with the ingested food and the products of excretion is what provides the functioning of every biochemical machinery of an organism [1].

The biggest part of these energetic transformations goes through the mitochondria, a complex organelle with a probable endosymbiotic origin developed from ancestral eukaryotic cells, which made possible the use of oxygen $\left(\mathrm{O}_{2}\right)$ in order to transfer the energy coming from food [4]. Evidence from this theory come from the fact that mitochondria are the only organelles that contain its own genome, the mitochondrial DNA (mtDNA) [5].

Besides the fact they are involved in energetic transformation provided by substrates, mitochondria also develop an important role as integrators of a variety of intracellular signals such as the regulation of reactive oxygen species (ROS), intrinsic pathways of apoptosis [6], regulation of ions of $\mathrm{Ca}^{2+}$ [7], besides genic retrograde control [8].

With its importance, it is not surprising to know that mitochondria also are sensitive to diverse intrinsic stressor agents such as the mutation and deletion of the nuclear desoxyribonucleic acid (DNA) or mtDNA
[9], privation or excess of energetic substrates [10], increase of ROS [11] and also to stressor extrinsic agents, such as toxins, viruses, bacteria and ultraviolet rays [2]. These agents can alter both mitochondrial function and dynamic that integrate many pathways aiming the necessary energy supply so that the cell is able to adapt to these stressor agents [9].

Besides that, this interesting organelle is considered an important local generator of systemic responses [12]. New evidence has pointed mitochondria as a local of larger genic repertoire. These findings involve the discovery of two peptides named Humanin and mitochondrial open Reading frame (ORF) of the twelve S-c (MOTS-c), which are derivative from mtDNA and have an important systemic performance, breaking paradigms in relation to the physical intracellular space of mitochondrial operation $[13,14]$.

Few works have accomplished studies regarding mitochondrial systemic responses practiced by mitochondrial peptides faced with controlled stress, such as physical stress. Therefore, the goal of this review is to describe the biological effects of these two mitochondrial peptides as well as possible benefic interactions between them and the physical exercise. Considering studies pointing that the regulation of this new group of peptides is mediated by stress events $[15,16]$ enhancing its therapeutic potentials in the combat against Alzheimer disease [17] and Diabetes Mellitus [18], bringing possible insights to future clinic studies.

${ }^{\star}$ Correspondence to: Gilberto Eiji Shiguemoto, Federal University of São Carlos - UFSCar, Highway Washington Luis, Km 235 - SP 310, São Carlos, São Paulo, Brazil, E-mail: gileiji@gmail.com

Key words: mitochondria-derived peptides, physical exercise, metabolism, stress

Received: October 20, 2019; Accepted: November 15, 2019; Published: November 22, 2019 
This work was assisted by four bases of bibliographic data: PubMed, Web of Science, Scientific Electronic Library Online (SciELO) and Latin American and Caribbean Health Sciences Literature (LILACS), in the Portuguese and English languages.

It was considered a total of 76 scientific references with the focus on the mitochondrial peptides Humanin and MOTS-c and its biological effects, besides possible interactions with physical exercises. In relation to the utilized term, after differences were verified in the bibliographic database responsible for decrease the number of references, it was made the choice to use free terms, without the use of controlled vocabulary (descriptors), thus making it possible to guarantee the detection of a great deal of works published within the previously established criteria. In such way, it was applied the following combination of terms: "Mitochondria and Humanin"; "Mitochondria and MOTS-c"; "Exercise and Humanin"; "Exercise and MOTS-c"; "MOTS and effects biological"; "Humanin and effects biological" and "Mitochondrial Function" with associations and outcome of interest as proposed [19].

\section{Discovery of Open Reading Frames (ORF)}

In the literature it is common to find reference to products of mitochondrial transcription. They say the mtDNA is a circular structure that encodes 11 messenger RNAs (which translate 13 proteins), 2 ribosomal RNAs and 22 transporter RNAs [20]. However, in the nuclear and mitochondrial DNA there are places in which it is possible to codify peptides of less than 100 codons called open reading frames (ORF) potentially able to be translated into peptides and small proteins. A lot from these peptides in eukaryotic cell have its origin from larger proteins and suffer some kind of processing, but in the human genome there are hundreds to thousands of places capable to transcript these small peptides [21].

The transcript peptides in these regions of difficult investigation, and are named smORF (for small), can have biochemical activity, cellular or physiological in experiments, indicating its biological relevance [22]. It is important to stress that as well as the nuclear genome, the mitochondrial genome also have these structural open reading spaces, being identified transcripts of protein of systemic action, known as mitochondrial-derived peptides (MDPs), among others, Humanin e MOTS-c as the most notorious of them [21].

\section{Biological effects of Humanin}

Humanin was the first smORFs to be discovered in the mtDNA [23], associated to a survival state in cerebral cells from Alzheimer disease. It is transcript in a mitochondrial genic region known as $16 \mathrm{~S}$ rRNA or MT-RNR2 [24]. Structurally, Humanin is a 24 amino acid peptide, expressed in many tissues and it can be found in the blood stream of both rodents and human beings, presenting an expression decline related to the increase of age $[15,24]$.

Two interesting studies point the ways cellular death caused by Alzheimer disease can be avoided. A study of Ikonen et al., [25] showed that Humanin interacts with the insulin-like growth factor binding protein 3 (IGFBP-3) in rodents. IGFBP-3 belongs to a group of families responsible for transporting insulin-like growth 1 (IGF-1) and has many physiological actions independent from this transportation, such as proliferation, death and cellular survival $[26,27]$. Interacting with this protein, Humanin can block the induced cellular death by IGFBP-3 in cells [25], working as a protector effect.

Besides that, Humanin is able to interact with BAX, a key protein in the apoptosis process, avoiding its translocation to the mitochondria, suppressing the signaling cascade of apoptosis [28].
The levels of Humanin decrease with the aging [29] and studies in human muscle samples showed that older subjects have a drop in total mitochondrial mass [30]. These changes in quantity and molecular mitochondrial products can increase the sarcopenia case [31], with the root of other functional loses, such as mobility, independence, breathing, metabolic, etc. [32], being physical activity as one important non-pharmacological tool to delay such events [33].

\section{Exercise and Humanin}

Few studies were developed regarding this issue. In our research we find a single study that investigated the Humanin response to the intervention of physical exercise. In this study the authors Gidlund et al. [34] investigated the effects of resistance training (RT) in subjects with disfunction in the regulation of glucose levels. The RT was done for the great muscle groups in a periodizing linear model, with increase of weights over the course of weeks, reaching the weight of $80-90 \%$ of a maximum repetition (1RM) in the last two weeks. Besides this protocol, the authors also investigated the effect of the cyclical cardio exercise of Nordic walking, which involves the use of canes, in an also linear periodizing, using as intensity parameter the reserve cardiac frequency, reaching $75 \%$ of this variable in the last two weeks. To both protocols, the time used for the activities was 60 minutes three times a week. The authors investigated the serum and muscle levels of Humanin, as well as the genic expression 16S rRNA (MT-NRN2) which contains the open reading structures for Humanin transcription. In this intervention model, the authors found a significative increase of Humanin muscle content level in the RT group and corelated this result to a better tolerance to glucose in this group, indicating an endocrine Humanin effect.

In this sense, Muzumdar et al. [24] also found positive effects of Humanin administration in Diabetic animal models. The authors conclude that Humanin and its analogues have a therapeutic potential to better insulin action.

\section{Biological effects of MOTS-c}

MOTS-c is a peptide recently discovered by Lee et al. [35], containing 16 amino acids encoded by the genic region $12 \mathrm{~S}$ rRNA mitochondrial or MT-RNR1, and it is expressed mainly in the muscle skeletal tissue, but also it is found in other tissues as well as it is detected in the blood plasma, both in rodents and human beings [14]. This peptide performs various functions, as an important cytoprotector in helping to maintain the mitochondrial function and the cellular viability under stressful conditions, regulating the metabolic homeostasis [14,29]. The treatment in mice with MOTS-c showed itself as capable to avoid age resistance to insulin and also obesity induced by a diet rich in fat [36].

Lee et al. [14] studies investigated the possible subjacent effects to MOTS-c in cells in culture and in mice. The studies pointed that between its operation mechanisms is the interference in the biosynthesis pathway of purine. It happens through the inhibition of the genic expression of important enzymes that use as cofactor the folate, being its main active form the 5-methyl-tetrahydrofolate (5Me-THF), which is cofactor of important involved in many pathways such as the catabolism of amino acids and biosynthesis of purines [37].

Since MOTS-c inhibits indirectly the biosynthesis of purines, there is an elevation of AICAR (5-aminoimidazole-4-carboxamide ribonucleotide), an intermediate of purine synthesis. This increase in AICAR activates the kinase activated by 5 ' adenosine monophosphateactivated protein kinase (AMPK), which enhances the fat oxidation [38]. The AMPK also inhibits the Aceti-CoA - Carboxilase, which its 
function is transforming Acetil-Coa in Malonil-Coa - and this last one performs an allosteric inhibitory effect in the Palmitoil-Transferase 1 [14,37]. So, when AICAR inhibits Acetil-CoA-Carboxilase, it allows that more fatty acids enter in the mitochondria and be available for the $\beta$-oxidation. These catabolic effects combined increase the lipolysis, reduce the lipogenesis and increase the reception of glucose [39].

Even more interesting, AMPK activates the coactivator alpha 1 of the Peroxisome proliferator-activated receptor-gamma coactivator (PGC$1 \alpha)$, which is a coactivator of genic transcription $[40,41]$. Between the nuclear transcription targets of PGC- $1 \alpha$, there is the Nuclear respiratory factor (NRF-1 e NRF-2) and members of the Peroxisome proliferatoractivated receptor (PPAR), all of them involved with the increase of proteins that regulate or are part of the mitochondrial structure. One of the NFR-1 products is the Mitochondrial transcription factor A (TFAM) that goes to the mitochondria increasing the transcription of mitochondrial gens [42].

Furthermore, rodents treated with injections of MOTS-c presented an increase of heat production and energetic consumption [35]. This is analogue to the increase of the activity of uncoupler proteins (UCPs), which are activated by the stimulation adrenergic of the sympathetic nerves that innervate the adipose brown tissue an increase the activity of the second messenger cyclic adenosine 3', 5'-monophosphate (cAMP). This activates the AMPK that accelerates catabolic pathways with the lipolysis and increases the transcription of UCP-1 [43]. This adaptive mechanism refers to the thermogenic process of dissipation of heat and increase of body temperature, resultant of the adenosine triphosphate (ATP) synthesis decoupling through the leak of protons from the internal mitochondrial membrane, known as thermogenesis without tremor [44,45], which can explain the increase of the energetic consumption and production of heat. If MOTS-c is able to increase the activity and expression of UCPs it is a scenario to be further investigated.

\section{MOTS-c and physical exercise}

The survival of human species through the centuries depended on the execution of motor tasks, whether it was for labor activities in more recent centuries or the acquisition of nourishment in more distant ones, this way the genetic selection through the evolutive periods, very likely, suffered great influence of stress caused by physical activity [46].

It is known that the mitochondria are the main bioenergetic sources during the physical activities and, beyond that, they have a central role in the signaling of physical activity to other organs. So, it is important to notice the possible of MOTS-c potential faced with all the transmission and signaling net due to physical stress [36]. The effect of the different kinds of physical activity about the regulation and secretion of MOTS-c need additional studies [38], however it is important to emphasize the intracellular molecular pathways, that after receiving external stimulations, transmit epigenetic messages [47].

Unfortunately, because of its recent discovery, it was not found studies that analyzed the effect of physical activity intervention and the MOTS-c response. Nonetheless, some essays emulate through the application of MOTS-c, some benefits that are typically attributed to physical activity [13], leaving more than one suspicion that this peptide is an important signal in exercise physical.

For example, our research group has already showed that the ovariectomy promotes a case of dyslipidemia [48,49] and increase in body mass [50], both related to the risk of increase of metabolic syndrome. In all these works, a RT protocol was able to reduce said risks. In similar fashion, a work of Lu et al. [51] has showed that rats that underwent an ovariectomy and were treated with MOTS-c had prevention in terms of increasing body mass in the group. Besides, the OVX-MOTS-c group showed higher activity of the brown adiposus tissue, evaluated by means of mitochondrial markers how the increase of the expression PGC-1 1 , UCP-1, number and quantities of mitochondrial crista. It is also interesting that our groups have also showed an increase of PGC-1 $\alpha$ expression in the OVX group trained in the skeletal muscle tissue, like what happened in administration with MOTS, however evaluated in different tissues [52].

Another RT effect known is to prevent and treat cases of osteoporosis and osteopenia [53-55] common in low levels of estrogen, both in the animal model of ovariectomy [56-59] as in studies with humans [54,60]. In this contexto, MOTS-c also mimicked the effects of physical exercise, being able to prevent significantly the loss of bone mass induce by ovariectomy analyzed by means of micro-CT [61]. The role of MOTS-c as a prevention factor for bone loss in this study is related trough the inhibition of osteoclast formation induced by receptor activator of nuclear factor kappa-B ligand (RANKL) via activation of AMPK. Between the physiological effects that MOTS-c promote and that emulate physical exercise effects, it is worth to mention the inhibition of the increase differentiation of osteoclasts [61-63] and reduction of proinflammatory cytokines in animal models $[51,52]$.

Another pathway that must be investigated regarding the operation of MOTS-c is its ability of increasing the quantity of AICAR (5-aminoimidazole-4-carboxamide ribonucleotide). As seen in the subitem MOTS-c biological effects, in the study led by Lee et al. [35], the metabolites in cells in culture showed reduction in the levels of active folate, $5 \mathrm{Me}$-THF, molecule that is enzymatic coactivator of nucleotides biosynthesis. The reduction of $5 \mathrm{Me}-\mathrm{THF}$ increased levels of AICAR, intermediate of the synthesis "de novo" nucleotides, that also has many metabolic effects [39].

AICAR is an agonist of AMPK, well studied in animal models. AMPK activity increases when has decreased ATP levels occurs. Between targets AMPK we have PPAR-a [64] and PPAR- $\Delta$ [65] PGC$1 \alpha$ [66], which are pathways that lead to the increase of the energetic contribution of catabolic pathways, similar to what happens in the physical exercise. Equivalent to the adaptation process that happen in the physical exercise, administration of AICAR enhanced in $44 \%$ the performance of mice running in the treadmill then control group [65].

The physical exercise canalizes to similar pathways such as the ones described above because it increases the energetic demand required to the achievement of physical exercise, elevating the levels of the relation adenosine monophosphate (AMP)/ATP that activate AMPK [39], PGC-1a [67] and PPAR- $\gamma$ [35].

These described pathways could be the link between the new group of MOTS-c and mitochondria adaptations that aim to provide energetic supply to the cell, as well as converging to important metabolic adaptations. MOTS-c better the glucose tolerance in animals [35] and physical exercise in human too [68]. MOTS-c better metabolic conditions in diets rich in fat [35] as well as in physical exercise [69], both in animal models. Besides, MOTS-c increases cellular levels of AICAR [35] the same way the physical exercise increases AMPK levels [70], which is activated by AICAR. So, it is plausible that interconnected pathways happens in the administration of MOTS-c and also in the physical exercise. However, if MOTS-c is a signal of physical exercise it is an issue that must be verified in future studies. 


\section{Future Insights}

Mitochondria are organelles involved in stress response due to the need to provide energy to restore homeostasis and are necessary to integrate acute and chronic needs for ATP demands [2,71]. Mitochondrial responses to stress are known as mitohormesi, term derived from a description of biphasic response to exposure to stressors, where exposure low dose causes beneficial effect and high exposure causes deleterious effects.

From an adaptive point of view, these disturbances are transmitted to the cytosol, nucleus [3] and to a level still poorly understood that generates systemic responses directed at other tissues or organs [14]. These stressor agents that alter mitochondrial function may contribute to increased mitochondrial ROS as well as other mediators that induce mitohormesi [71].

In this sense, physical exercise can act as a stressor because it alters the body's energy needs. For example, in physical exercise there is an increase in body temperature, reflecting energy loss as heat [3]. In addition, changes in $\mathrm{O}_{2}$ consumption levels alter ROS production. This is evidenced by increased production of ROS during exercise and paradoxically in immobilization [72].

Most protocols of large institutes recommend levels of moderate aerobic physical exercise of at least 30 minutes with frequency of 5 times a week or aerobic activity the vigorous intensity for at least 20 minutes with frequency of 3 times a week for maintenance and improved health for the general population $[53,73]$. The intensity of these activities should be related to some physiological equivalent, such as heart rate, Metabolic Equivalent of Task (MET), percentage of maximum $\mathrm{O}_{2}$ uptake, or with respect to some parameter of the motor task such as speed, time, etc. [74].

In this sense, so that physical exercise intervention to be effective, it must be manipulated in a planned way considering the components of the training load (periodization) such as: volume, intensity, density, frequency and training method; such variables may result in different mitochondrial stresses and responses mitochondrial [75], which may influence the release of the new class of mitochondrial peptides.

However, we emphasize that new studies are necessary in the search for understanding about these new mitochondrial peptides and their possible interactions with physical exercise, which in the future may become potential therapeutic agents in the fight against some diseases. As an example, we can mention irisine, a myocin released into the blood stream during exercise and that has a systemic action, being able to increase the expression of brain-derived neurotrophic factor (BDNF) in the hippocampus region responsible for learning and memory in models animals, making the irisine in recent years to gain notoriety due to its potential neuroprotective action [76].

Thus, we hope that the present review may raise the interest of new clinical studies that better investigate the responses of this new class of peptides faced intervention of the physical exercise, considering the correct manipulation of the components of the training load that modulate both Humanin's response and MOTS-c's response, with therapeutic potential in combating various diseases.

\section{References}

1. Silberberg MS, Amateis P (1996) Chemistry: The molecular nature of matter and change. St. Louis, Missouri, USA: Mosby.

2. Eisner V, Picard M, Hajnóczky G (2018) Mitochondrial dynamics in adaptive and maladaptive cellular stress responses. Nat Cell Biol 20: 755-765. [Crossref]
3. Picard M, McEwen BS, Epel ES, Sandi C (2018) An energetic view of stress: Focus on mitochondria. Front Neuroendocrinol 49: 72-85. [Crossref]

4. Othman S (2017) The Mitochondrion: The Prisoner of a False Origin and The Victim of Wrong Theories. Enliven: J Genet Mol Cell Biol 4: 002.

5. Kang D, Kim SH, Hamasaki N (2007) Mitochondrial transcription factor A (TFAM): Roles in maintenance of mtDNA and cellular functions. Mitochondrion 7: 39-44. [Crossref]

6. Hepple RT (2014) Mitochondrial involvement and impact in aging skeletal muscle. Front Aging Neurosci 6: 211. [Crossref]

7. Gunter TE, Gunter KK (2002) Uptake of calcium by mitochondria: Transport and possible function. IUBMB Life 52: 197-204. [Crossref]

8. Matilainen O, Quirós PM, Auwerx J (2017) Mitochondria and Epigenetics - Crosstalk in Homeostasis and Stress. Trends Cell Biol 27: 453-463. [Crossref]

9. Suomalainen A, Battersby BJ (2018) Mitochondrial diseases: The contribution of organelle stress responses to pathology. Nat Rev Mol Cell Biol 19: 77-92. [Crossref]

10. Liesa M, Shirihai OS (2013) Mitochondrial dynamics in the regulation of nutrient utilization and energy expenditure. Cell Metab 17: 491-506. [Crossref]

11. Brand MD (2016) Mitochondrial generation of superoxide and hydrogen peroxide as the source of mitochondrial redox signaling. Free Radic Biol Med 100: 14-31. [Crossref]

12. Kowaltowski AJ (2004) Participação da mitocôndria na regulação da viabilidade celular (Doctoral thesis, Universidade de São Paulo).

13. Kim SJ, Xiao J, Wan J, Cohen P, Yen K (2017) Mitochondrially derived peptides as novel regulators of metabolism. J Physiol 595: 6613-6621. [Crossref]

14. Lee C, Kim KH, Cohen P, Angeles L (2016) MOTS-c: A novel mitochondrial-derived peptide regulating muscle and fat metabolism. Free Rad Biol Med 100: 182-187. [Crossref]

15. Bachar AR, Scheffer L, Schroeder AS, Nakamura HK, Cobb LJ, et al. (2010) Humanin is expressed in human vascular walls and has a cytoprotective effect against oxidized LDL-induced oxidative stress. Cardiovasc Res 88: 360-366. [Crossref]

16. Jia Y, Lue YH, Swerdloff R, Lee KW, Cobb LJ, et al. (2013) The cytoprotective peptide humanin is induced and neutralizes Bax after pro-apoptotic stress in the rat testis. Andrology 1: 651-659. [Crossref]

17. Koide T, Tsuji S, Sobue G, Hashimoto Y, Kita Y, et al. (2002) A rescue factor abolishing neuronal cell death by a wide spectrum of familial Alzheimer's disease genes and Abeta. Proc Natl Acad Sci U S A 98: 6336-6341. [Crossref]

18. Kuliawat R, Klein L, Gong Z, Nicoletta-Gentile M, Nemkal A, et al. (2013) Potent humanin analog increases glucose-stimulated insulin secretion through enhanced metabolism in the cell. FASEB J 27: 4890-4898. [Crossref]

19. Sin DD, McAlister FA, Man SF, Anthonisen NR (2003) Contemporary management of chronic obstructive pulmonary disease: scientific review. JAMA 290: 2301-2312. [Crossref]

20. Gustafsson CM, Falkenberg M, Larsson NG (2016) Maintenance and Expression of Mammalian Mitochondrial DNA. Аnпu Rev Biochem 85: 133-160. [Crossref]

21. Saghatelian A, Couso JP (2015) Discovery and characterization of smORF-encoded bioactive polypeptides. Nat Chem Biol 11: 909-916. [Crossref]

22. Basrai MA, Hieter P, Boeke JD (1997) Small Open Reading Frames: Beautiful Needles in the Haystack. Genome Res 7: 768-771. [Crossref]

23. Hashimoto Y, Ito Y, Niikura T, Shao Z, Hata M, et al. (2001) Mechanisms of neuroprotection by a novel rescue factor humanin from Swedish mutant amyloid precursor protein. Biochem Biophys Res Commun 283: 460-468. [Crossref]

24. Muzumdar RH, Huffman DM, Atzmon G, Buettner C, Cobb LJ, et al. (2009) Humanin: A Novel Central Regulator of Peripheral Insulin Action. PLoS ONE 4: e6334. [Crossref]

25. Ikonen M, Liu B, Hashimoto Y, Ma L, Lee KW, et al. (2003) Interaction between the Alzheimer's survival peptide humanin and insulin-like growth factor-binding protein 3 regulates cell survival and apoptosis. Proc Natl Acad Sci U S A 100: 13042-13047. [Crossref]

26. Almeida OP, Hankey GJ, Yeap BB, Paul Chubb SA, Gollege J, et al. (2018) Risk of prevalent and incident dementia associated with insulin-like growth factor and insulinlike growth factor-binding protein 3. Mol Psychiatry 23: 1825-1829. [Crossref]

27. Baxter RC (2013) Insulin-like growth factor binding protein-3 (IGFBP-3): Nove ligands mediate unexpected functions. J Cell Commun Signal 7: 179-189. [Crossref] 
28. Guo B, Zhai D, Cabezas E, Welsh K, Nouraini S, et al. (2003) Humanin peptide suppresses apoptosis by interfering with Bax activation. Nature 423: 456-461. [Crossref]

29. Mendelsohn AR, Larrick JW (2018) Mitochondrial-Derived Peptides Exacerbate Senescence. Rejuvenation Res 21: 369-373. [Crossref]

30. Welle S, Brooks AI, Delehanty JM, Needler N, Thornton CA (2015) Gene expression profile of aging in human muscle. Physiol Genomics 14: 149-159. [Crossref]

31. Marzetti E, Calvani R, Cesari M, Buford TW, Lorenzi M, et al. (2013) Mitochondrial dysfunction and sarcopenia of aging: From signaling pathways to clinical trials. Int $J$ Biochem Cell Biol 45: 2288-2301. [Crossref]

32. Rosenberg IH (1997) Sarcopenia: Origins and Clinical Relevance. J Nutr 127: 990-991. [Crossref]

33. Ambrose KR, Golightly YM (2015) Physical exercise as non-pharmacological treatment of chronic pain: Why and when. Best Pract Res Clin Rheumatol 29: 120-130 [Crossref]

34. Gidlund EK, Von Walden F, Venojärvi M, Risérus U, Heinonen OJ, et al. (2016) Humanin skeletal muscle protein levels increase after resistance training in men with impaired glucose metabolism. Physiol Rep 4: e13063. [Crossref]

35. Lee C, Zeng J, Drew BG, Sallam T, Martin-Montalvo A, et al. (2015) The MitochondrialDerived Peptide MOTS-c Promotes Metabolic Homeostasis and Reduces Obesity and Insulin Resistance. Cell Metabolism 21: 443-454. [Crossref]

36. Zarse K, Ristow M (2015) A mitochondrially encoded hormone ameliorates obesity and insulin resistance. Cell Metab 21: 355-356. [Crossref]

37. Nelson DL and Cox MM. (2017) Principles of Biochemetry of Lehninger. 7th ed, New York: McMillan Learning.

38. Fuku N, Pareja-Galeano H, Zempo H, Alis R, Arai Y, et al. (2015) The mitochondrialderived peptide MOTS-c: A player in exceptional longevity? Aging Cell 14: 921-923. [Crossref]

39. Richter EA, Ruderman NB (2009) AMPK and the biochemistry of exercise: implications for human health and disease. Biochem J 418: 261-275. [Crossref]

40. Mericskay M, Moulin M, Lemaire C, Ventura-Clapier R, Piquereau J, et al. (2017) Mitochondria: a central target for sex differences in pathologies. Clin Sci (Lond) 131: 803-822. [Crossref]

41. Thirupathi A, de Souza CT (2017) Multi-regulatory network of ROS: the interconnection of ROS, PGC-1 alpha, and AMPK-SIRT1 during exercise. J Physiol Biochem 73: 487494. [Crossref]

42. Klinge CM (2009) NIH Public Access. 105: 1197-1218.

43. Divakaruni AS, Brand MD (2011) The regulation and physiology of mitochondrial proton leak. Physiology (Bethesda) 26: 192-205. [Crossref]

44. Busiello RA, Savarese S, Lombardi A (2015) Mitochondrial uncoupling proteins and energy metabolism. Front Physiol 6: 36. [Crossref]

45. Ricquier D, Kader JC (1976) Mitochondrial protein alteration in active brown fat: A sodium dodecyl sulfate-polyacrylamide gel electrophoretic study. Biochem Biophys Res Commun 73: 577-583. [Crossref]

46. Chakravarthy MV, Booth FW (2004) Eating, exercise, and "thrifty" genotypes: connecting the dots toward an evolutionary understanding of modern chronic diseases. J Appl Physiol 96: 3-10. [Crossref]

47. Pilegaard H, Saltin B, Neufer DP (2003) Exercise induces transient transcriptional activation of the PGC-1a gene in human skeletal muscle. $J$ Physiol 546: 851-858. [Crossref]

48. Leite RD, Prestes J, Bernardes CF, Shiguemoto GE, Pereira GB, et al. (2009) Effects of ovariectomy and resistance training on lipid content in skeletal muscle, liver, and heart; fat depots; and lipid profile. Appl Physiol Nutr Metab 34: 1079-1086. [Crossref]

49. Stotzer US, Rodrigues MFC, Domingos MM, Silva GHG, Duarte FO, et al. (2015) Resistance training suppresses intra-abdominal fatty acid synthesis in ovariectomized rats. Int J Sports Med 36: 226-233. [Crossref]

50. Monteiro ARB (2019) Efeito do Treinamento Resistido na Função Mitocondrial e na Expressão Gênica da UCP-3 no Músculo de Ratas Ovariectomizadas (Master dissertation, Federal University of São Carlos).

51. Lu H, Lu Z, Yang Y, Yan Z, Zhai D, et al. (2017) MOTS-c peptide increases survival and decreases bacterial load in mice infected with MRSA. Mol Immunol 92: 151-160. [Crossref]
52. Barbosa MR, Shiguemoto GE, Tomaz LM, Ferreira FC, Rodrigues MFC, et al. (2016) Resistance Training and Ovariectomy: Antagonic Effects in Mitochondrial Biogenesis Markers in Rat Skeletal Muscle. Int J Sports Med 37: 841-848. [Crossref]

53. Garber CE, Blissmer B, Deschenes MR, Franklin BA, Lamonte MJ, et al. (2011) Quantity and quality of exercise for developing and maintaining cardiorespiratory, musculoskeletal, and neuromotor fitness in apparently healthy adults: Guidance for prescribing exercise. Med Sci Sports Exerc 43: 1334-1359. [Crossref]

54. Kemmler W, Von Stengel S, Kohl M (2016) Exercise frequency and bone mineral density development in exercising postmenopausal osteopenic women. Is there a critical dose of exercise for affecting bone?? Results of the Erlangen Fitness and Osteoporosis Prevention Study. Bone 89: 1-6. [Crossref]

55. Pasqualini L, Ministrini S, Lombardini R, Bagaglia F, Paltriccia R, et al. (2019) Effects of a 3-month weight-bearing and resistance exercise training on circulating osteogenic cells and bone formation markers in postmenopausal women with low bone mass. Osteoporosis Int 30: 797-806. [Crossref]

56. Kim T, Won J, Geun B, Min J, Kyun E, et al. (2011) The effects of luteolin on osteoclast differentiation, function in vitro and ovariectomy-induced bone loss. $J$ Nutr Biochem 22: 8-15. [Crossref]

57. Pacifici R (2012) Role of T cells in ovariectomy induced bone loss--revisited. J Bone Miner Res 27: 231-239. [Crossref]

58. Shiguemoto GE, Prestes J, Leite RD, Pereira GB, Pontes CLS, et al. (2012) Effects of resistance training on matrix metalloproteinase-2 activity and biomechanical and physical properties of bone in ovariectomized and intact rats. Scand J Med Sci Sports 22: 607-617. [Crossref]

59. Souza MVC, Lino ADS, Ruffoni LGD, Domingos MM, Barbosa MR, et al. (2017) Resistance training and hormone replacement increase MMP-2 activity, quality and quantity of bone in ovariectomized rats. Motriz 23: 1-8

60. Ishibashi H, Crittenden DB, Miyauchi A, Libanati C, Maddox J, et al. (2017) Romosozumab increases bone mineral density in postmenopausal Japanese women with osteoporosis: A phase 2 study. Bone 103: 209-215. [Crossref]

61. Ming W, Lu G, Xin S, Huanyu L, Yinghao J, et al. (2016) Mitochondria related peptide MOTS-c suppresses ovariectomy-induced bone loss via AMPK activation. Biochem Biophys Res Commun 476: 412-419. [Crossref]

62. Kim SJ, Mehta HH, Wan J, Kuehnemann C, Chen J, et al. (2018) Mitochondrial peptides modulate mitochondrial function during cellular senescence. Aging (Albany NY) 10: 1239-1256. [Crossref]

63. Kang YS, Kim CH, Kim JS (2017) The effects of downhill and uphill exercise training on osteogenesis- related factors in ovariectomy- induced bone loss. J Exercise Nutrition Biochem 21: 1-10. [Crossref]

64. Bronner M, Hertz R, Bar-Tana J (2004) Kinase-independent transcriptional coactivation of peroxisome proliferator-activated receptor a by AMP-activated protein kinase. Biochem J 384: 295-305. [Crossref]

65. Narkar VA, Downes M, Yu RT, Embler E, Wang YX, et al. (2008) AMPK and PPARdelta agonists are exercise mimetics. Cell 134: 405-415. [Crossref]

66. Jager S, Handschin C, St.-Pierre J, Spiegelman BM (2007) AMP-activated protein kinase (AMPK) action in skeletal muscle via direct phosphorylation of PGC-1. Proc Natl Acad Sci U S A 104: 12017-12022. [Crossref]

67. Baar K, Wende AR, Jones TE, Marison M, Nolte LA, et al. (2002) Adaptations of skeletal muscle to exercise: rapid increase in the transcriptional coactivator PGC-1. FASEB J 16: 1879-1886. [Crossref]

68. Way KL, Keating SE, Baker MK, Chuter VH, Johnson NA (2016) The Effect of Exercise on Vascular Function and Stiffness in Type 2 Diabetes: A Systematic Review and Meta-analysis. Curr Diabetes Rev 12: 369-383. [Crossref]

69. Bradley RL, Jeon JY, Liu FF, Maratos-Flier E (2008) Voluntary exercise improves insulin sensitivity and adipose tissue inflammation in diet-induced obese mice. $\mathrm{Am} \mathrm{J}$ Physiol Endocrinol Metab 295: E586-E594. [Crossref]

70. Fujii N, Hayashi T, Hirshman MF, Smith JT, Habinowski SA, et al. (2000) Exercise induces isoform-specific increase in 5' AMP-activated protein kinase activity in human skeletal muscle. Biochem Biophys Res Commun 273: 1150-1155. [Crossref]

71. Yun J, Finkel T (2014) Mitohormesis. Cell Metab 19: 757-766. [Crossref]

72. Powers SK, Duarte J, Kavazis AN, Talbert EE (2010) Reactive oxygen species are signalling molecules for skeletal muscle adaptation. Exp Physiol 95: 1-9. [Crossref] 
73. Church TS, Earnest CP, Skinner JS, Blair SN (2007) Effects of different doses of physical activity on cardiorespiratory fitness among sedentary, overweight or obese postmenopausal women with elevated blood pressure: a randomized controlled trial. JAMA 297: 2081-2091. [Crossref]

74. Haskell WL, Lee IM, Pate RR, Powell KE, Blair SN, et al. (2007) Physical activity and public health: updated recommendation for adults from the American College of Sports Medicine and the American Heart Association. Circulation 116: 1081-1093. [Crossref]
75. Diniz TA, Rossi FE, Buonani C, Mota J, Freitas-Junior IF (2017) Exercício físico como tratamento não farmacológico para a melhora da saúde pós-menopausa. Revista Brasileira de Medicina Do Esporte 23: 322-327.

76. Lourenco MV, Guerra LA, Wilcock DM, Kincheski GC, Alves-Leon S, et al. (2018) Exercise-linked FNDC5/irisin rescues synaptic plasticity and memory defects in Alzheimer's models. Nat Med 25: 165-175. [Crossref]

Copyright: (C2019 Monteiro ARB. This is an open-access article distributed under the terms of the Creative Commons Attribution License, which permits unrestricted use, distribution, and reproduction in any medium, provided the original author and source are credited. 